\title{
NEONATAL, INTRAUTERINE OR CUSTOMISED BIRTH WEIGHT STANDARDS TO PREDICT COGNITIVE AND SCHOOL OUTCOMES IN VERY PRETERM CHILREN. DATA FROM THE EPIPAGE COHORT STUDY
}

\author{
M.-L. Charkaluk ${ }^{1,2,3}$, S. Carvalho ${ }^{2}$, A. Ego ${ }^{4}$, P. Truffert ${ }^{1,5}$, L. Marchand-Martin ${ }^{1}$, P.-Y. Ancel ${ }^{1,3}$, V. Pierrat ${ }^{1,5}$ \\ ${ }^{I}$ Research Unit on Perinatal Health and Women's and Children's Health, INSERM UMR S 953 IFR 69, \\ Paris, ${ }^{2}$ Clinique de Pediatrie Saint Antoine, Groupe Hospitalier de l'Institut Catholique Lillois, Faculte \\ Libre de Medecine, Lille, ${ }^{3}$ UPMC Univ Paris 06, Paris, ${ }^{4}$ DMIS, REHOP, CHU Grenoble, Grenoble, ${ }^{5}$ Service \\ de Medecine Neonatale, Hopital Jeanne de Flandre, Lille, France
}

Background: Being born small for gestational age (SGA) is associated with developmental disabilities but associations may vary depending on the definition of SGA.

Aim: To analyse the impact of this definition on the relation between SGA and cognitive or school outcome.

Methods: 980 singletons born before 33 weeks in 1997 in France, part of the Epipage study, free of cerebral palsy, were classified SGA when birth weight was $<10^{\text {th }}$ percentile, according to 3 French standards: 1 . neonatal standard: nSGA or nAGA; 2. intrauterine standard using Hadlock's formula: fSGA or fAGA; 3. customised standard taking into account maternal characteristics: cSGA or cAGA.

Outcomes were cognitive dysfunction at age 5 defined as a score $<-1$ SD for the term control group (K-ABC battery), and school difficulties at age 8 .

Results: 149 children were nSGA (15.2\%), 368 fSGA (37.6\%) and 378 (38.6\%) cSGA. All nSGA children were fSGA and cSGA. Cognitive dysfunction was present in 300 children $(35.0 \%)$ and school difficulties in 173 (25.1\%). Children nAGA/fSGA did not have a significant increase of cognitive dysfunction compared to children nAGA/fAGA. Compared to children nAGA/fAGA, children nSGA/fSGA had an adjusted OR of school difficulties of 2.48 [1.52;4.05] while it was 1.63 [1.05;2.55] for children nAGA/fSGA. Children fAGA/cSGA $(\mathrm{N}=18)$ had a higher rate of school difficulties compared to children fAGA/cAGA $(p=0.03)$.

Conclusions: Intratuerine standard for birth weight is more appropriate than neonatal one to predict school outcome for very preterm singletons. The utility of customisation should be clarified. 